University of Nebraska - Lincoln

DigitalCommons@University of Nebraska - Lincoln

Faculty Publications, Department of Psychology

Psychology, Department of

January 2001

\title{
Hierarchical Classification and the Integration of Self-Structure in Late Adolescence
}

\author{
Eric B. Elbogen \\ Duke University Medical Center \\ Gustavo Carlo \\ University of Nebraska-Lincoln, carlog@missouri.edu \\ William D. Spaulding \\ University of Nebraska-Lincoln, wspaulding1@unl.edu
}

Follow this and additional works at: https://digitalcommons.unl.edu/psychfacpub

Part of the Psychiatry and Psychology Commons

Elbogen, Eric B.; Carlo, Gustavo; and Spaulding, William D., "Hierarchical Classification and the Integration of Self-Structure in Late Adolescence" (2001). Faculty Publications, Department of Psychology. 320.

https://digitalcommons.unl.edu/psychfacpub/320

This Article is brought to you for free and open access by the Psychology, Department of at DigitalCommons@University of Nebraska - Lincoln. It has been accepted for inclusion in Faculty Publications, Department of Psychology by an authorized administrator of DigitalCommons@University of Nebraska - Lincoln. 


\title{
Hierarchical Classification and the Integration of Self-Structure in Late Adolescence
}

\author{
Eric B. Elbogen, ${ }^{*}$ Gustavo Carlo, and William Spaulding \\ ${ }^{*}$ Corresponding author: Duke University Medical Center, Box 3071, \\ Durham, NC 27710; email eelbogen@psych.mc.duke.edu
}

\begin{abstract}
A number of empirical studies have demonstrated that one's self-concept is multidimensional in nature, varies according to social context, and shows increased differentiation throughout adolescence. There has been relatively less work, however, examining the integration of multi-dimensional social selves. Rosenberg and Gara's (1985) model of the multidimensional self (a model that utilizes a statistical procedure called "hierarchical classification" or HICLAS) was employed to investigate the integration of social selves during late adolescence. First- and fourth-year college students $(n=128)$ completed a computer program designed to collect data required to construct HICLAS "self-structures." The findings indicated that the social selves of fourth-year college students were more related conceptually and were more differentiated than the social selves of first-year students. The differences between first- and fourth-year students suggested that hierarchical classification procedures could be used to address developmental hypotheses.
\end{abstract}

\section{Introduction}

A century ago, William James (1892) posited that each individual constructs different self-conceptions for different social contexts, such as a spiritual self, a material self and a social self. George Kelly (1955) maintained that self-structure is hierarchical in nature and proposed that individuals define themselves differently in different contexts, thereby shaping the way people perceive the world. Erik Erikson (1968), in his account of personal identity, elaborated upon familial, ideological, friendship, occupational, and romantic selves. A number of researchers have since demonstrated that one's self-concept, self-worth, and self-attributes vary according to social context (Marsh, 1986; Markus and Nurius, 1986; Harter and Monsour, 1992). Modern conceptions of selfconcept therefore do not hold that one's self-concept is a unidimensional entity, but instead embrace the notion that self-structure is multi-dimensional in nature because it consists of different social self-conceptualizations or selves (Harter et al., 1997).

A number of longitudinal studies have shown that individuals become more differentiated and generate more social selves in adolescence (Damon and Hart, 1982; Harter, 1983). Among adolescents, the number of social selves has been found to increase with age (Montemeyer and Eisen, 1977; Byrne and Shavelson, 1996). Research has also shown that adolescents' descriptions of selfattributes depend on which social role they are being asked to describe (Harter and Monsour, 1992). Harter and Monsour maintained that both cognitive advances (see Fischer, 1980) and social- 
ization pressures (see Erikson, 1968) contribute to a more differentiated concept of self during adolescence. Some cross-sectional research has also investigated the differentiation of the multi-dimensional self in late adolescence and young adulthood, though this literature is less conclusive (see e.g. Berzonsky, 1989; Marsh, 1990).

In addition to self-differentiation, contemporary self-theorists have also examined the integration of self. From a cognitive-developmental perspective, "integration" has been defined as ". . . a capacity to synthesize apparently conflicting ideas or views into a more coherent whole, rather than feeling compelled to choose between them" (Berger, 1994, p. 467). With respect to the integration of self, several theorists have proposed that individuals synthesize their personal identity into a more coherent whole during the transition from late adolescence to young adulthood (Epstein, 1973; Grotevant, 1987; Waterman, 1988). Correspondingly, James Marcia (1966) proposed that individuals begin to consolidate various aspects of one's self during the college years. Indeed, Marcia's identity status model has been used to study self-integration in college students (e.g. Berzonsky, 1989). Other studies have confirmed that self-integration occurs during college years, though it was found that integration may vary as a function of cultural background (Strage, 1998).

There has been relatively less empirical work, however, examining the integration of multi-dimensional social selves. Two cross-sectional studies have indicated that the consolidation of multiple selves might impact one's affective experience of the self in adolescence (Strachan and Jones, 1982; Harter and Monsour, 1992). In both studies, researchers observed decreases in self-esteem and increases in reported self-conflict from ages 13 to 15 years, with a subsequent increase in selfesteem and a decrease in reported self-conflict by individuals 18 years of age. These findings imply that because late adolescents experience more comfort with their identity, they are better able to integrate the increased number of different selves than younger adolescents. Drawing from the work of Fischer (1980), Harter et al. (1997) suggested that the consolidation and coordination of self should be more likely in later adolescence because more abstract thinking would allow individuals to better resolve seeming contradictions within one's self-theory.

To our knowledge, there have been only a few empirical studies studying the integration of the multidimensional self in late adolescence. One set of studies is based on Linville's (1985) model of self-complexity in which individuals with greater self-complexity are hypothesized to possess a greater number of self-aspects and are able to maintain greater distinctions among self-aspects. In the model, a self-complexity measure is employed that involves participants matching traits to different self-aspects (i.e. social roles). In a repeated measures study, Linville (1987) found that college students with greater self-complexity scores were less prone to depression and to other psychological symptoms associated with stress. College students who scored higher on self-complexity measures have also been shown to demonstrate greater attentional resources (Conway and White-Dysart, 1999).

Another set of studies is based on Shavelson et al.'s (1976) model of self-concept. Shavelson et al. originally presented a model of multidimensional self in which the interrelationships between general academic (math, history, and science) and non-academic (emotional, social, and physical) self-concepts could be examined. Most of the empirical work on this model has focused on the academic self-concept and several cross-sectional studies have examined the differentiation and the integration of the academic self-concept in early and late adolescence (for a review, see Marsh, 1990). Byrne and Shavelson (1996) investigated a non-academic self-concept in a study of third, 
seventh, and eleventh graders and found that the older students demonstrated greater self-differentiation and self-integration.

Recently, Rosenberg and Gara (1985) proposed a model of the multi-dimensional self in which inter-relationships among a person's separate social selves are examined in order to capture an individual's "self structure." Rosenberg and Gara defined self-structure as an organization of different social selves, each of which was determined by different sets of descriptions. Different types of relations among the selves constitute set-theoretic relationships that can be used to generate a hierarchical class structure among different social selves (DeBoeck and Rosenberg, 1988; Mechelen and DeBoeck, 1995). Set-theoretic relationships have been used in the past to study self-perception and person-perception and have been part of theoretical discourse on personality organization and implicit belief systems (Epstein, 1973; D'Andrade 1976).

As such, the idea of self-structure combines important elements of both Linville's (1985) and Shavelson et al.'s (1976) models. Like Linville Rosenberg and Gara's (1985) model postulates a multidimensional self composed of a number of specific social identities. Like Shavelson et al., Rosenberg and Gara focus on the interrelationships of different aspects of the self. The potential benefit of set-theoretic relationships has led to the development of a formalized computer program called HICLAS by DeBoeck and Rosenberg (1988). Named after the statistical procedure called hierarchical classification, HICLAS is used in conjunction with Rosenberg and Gara's model in order to represent multiple identities in a structural manner. Data concerning a person's selves and related attributes are collected, compiled, and entered into the HICLAS program. The self-structure is then summarized in both a two-way matrix table and a graphical printout depicting the organization of different selves in a hierarchical manner. Because set-theoretic relationships between social selves constitute this hierarchical organization, HICLAS self-structure variables can be operationalized, permitting investigation of the integration of multidimensional selves.

To date, Rosenberg and Gara's (1985) theory of self-structure has mainly been used in studies investigating how identity is structured in individuals with psychiatric diagnoses, such as schizophrenia and major depression (see e.g. Gara, et al., 1987; Gara et al., 1989; Robey et al., 1989; Gara et al., 1993). In one cross-sectional study of non-clinical subjects aged 10-27 years, Haviland et al. (1994) used HICLAS to study the place of emotion in the self-structure models of adolescents. These researchers found that, within the self-structures, there was an indication that emotional change accompanied the discontinuities between social selves. In a case study of a 22-year-old female college student, HICLAS was used to understand how relational schemas and social selves were implicitly organized (Ogilvie et al., 1998).

These studies suggest that HICLAS could be used to empirically test relevant hypotheses about the integration of multidimensional social selves in late adolescence. The HICLAS program analyses set-theoretic relationships and generates a representation of the interrelationships between an individual's social selves, indicating facets of the multidimensional self-structure that can be studied empirically. The primary objective of the present study, therefore, was to examine self-concept in late adolescence employing the HICLAS procedure. As mentioned above, the transition into adulthood has been postulated by a number of self-theorists to involve the consolidation of personal identity. Further, research suggests that the self becomes more differentiated over the lifespan. It was therefore expected that older college students would demonstrate more integrated and differentiated HICLAS self-structures than younger college students. 


\section{Method}

Participants

Participants were 128 undergraduate students enrolled in a psychology course at a Midwestern state university. Included in the sample were 77 first-year students ( 49 female, 28 male) and 51 fourth-year students (27 female, 24 male). Socio-economic status was measured according to their parents' income and did not differ significantly between the two groups. The mean age for students in the first-year group was 18.6 years while the mean age for students in the fourth-year group was 22.4 years

\section{Procedure}

All participants entered data on a computer program called OMNIGRID-PC (Sewell and Heacock, 1991). OMNIGRID-PC is based upon Kelly's (1955) personal construct theory and is designed to generate repertory grids by asking participants to rate social selves on a number of descriptions (see Fransella and Bannister, 1977). Correspondingly, HICLAS studies have involved participants rating a number of social selves on a number of descriptions (Rosenberg and Gara, 1985). As a result, OMNIGRID can be used as a computer program to collect exactly the type of data required for HICLAS self-structures. Although HICLAS data has usually been collected with paper and pencil measures, Gara et al. (1989) acknowledged that HICLAS "makes considerable use of elements of personal construct theory" (p. 267). As such, using OMNIGRID-PC presents both a practical and a theoretically viable method for collecting HICLAS data.

In the current study, the social selves were supplied for participants in order to provide a wide array of dimensions of social selves. It was thought that greater variation in the types of social selves would yield more valuable information than would be the case if the dimensions of social selves were more limited in scope. Furthermore, the social selves were selected to be valid to use with a normative sample. Thus, social selves were derived from a variety of empirical studies, including research using normative college samples (Berzonsky and Neimeyer, 1988), normal adults (Rosenberg and Gara, 1985), and psychiatric populations (Robey et al., 1989). Finally, Byrne and Shavelson (1996) found that 14 selves were sufficient to examine hierarchical, multi-dimensional self-organization in a normative sample of late adolescents. Based on this and other prior empirical research, the social selves included in the current study were my self as: a daughter/son, a friend, a romantic partner, a helper, a healthy person, a student, a worker, a neighbor, an enemy, a patient, a brother/sister, a sick person, my ideal self, and I usually am.

Although the social selves were supplied, participants were asked to provide descriptions of these selves. First, OMNIGRID-PC created a random list of three of the aforementioned social selves and printed this list on the computer screen. Participants were then requested to describe how two of the social selves listed were different in some important way from the third (thus providing a description). Because OMNIGRID-PC was employed and because personal construct theory typically requests individuals to elucidate pairs of descriptions (e.g. Adam-Webber, 1985), participants were also asked to enter the opposite of the description so as to provide a description dyad (e.g., "caring/nonchalant"). It is important to note that this is a modification of typical HICLAS study procedures (which usually only require one word for the description rather than a dyad), but it is unclear that this would represent any major problems for interpreting the selfstructure. After creating the description dyad, the program then created a second random list of 
three of the aforementioned social selves. Participants were again requested to enter a description dyad. This process continued and repeated itself until 14 description dyads were provided.

After providing the 14 description dyads, participants were asked to rate their social selves on the description dyads they entered. Participants responded on a Likert Scale from 1-6, with "1" designating the first descriptor of the dyad entered (e.g. "caring") and "6" denoting the opposite or second descriptor of the dyad entered (e.g. "nonchalant"). Participants rated each of the different social selves on each of the description dyads they provided. This comprised the last stage of participant involvement in the research, completing the OMNIGRID-PC data collection. Administration of this entire procedure lasted approximately 30 minutes.

\section{Data transformation}

The OMNIGRID-PC 14_14 data matrix was translated into a HICLAS data matrix, which measures the structure of social selves in relation to one another. Subsequently, HICLAS assigns "0" for OMNIGRID-PC ratings of 1,2 or 3 and a " 1 " for ratings of 4,5 , or 6 . The binary representation of a HICLAS data matrix is illustrated in Table 1. The goodness of fit between the participants' ratings of social selves and the HICLAS data matrices was then calculated. When the HICLAS procedure is conducted, the researcher needs to choose a level of analysis, which means the level at which data matrices are converted into graphical representations. In other words, HICLAS can graphically represent the data in multiple ways. One can either choose a level of analysis that is the same for each participant or let the levels of analysis vary as a function of goodness of fit. In this study, the former approach was taken and the level of analysis was left constant for all participants. This level was set at the point when all the participants' HICLAS self-structures had a goodness of fit of above 0.90 , indicating that at least 90 per cent of the participants' ratings of the social selves on descriptions was accounted for by the HICLAS matrix. This level of goodness of fit has been considered sufficient for statistical analysis of HICLAS data (see Rosenberg and Gara, 1985).

Finally, a hierarchical classification procedure that generated hierarchical structures of social selves and descriptions was conducted (DeBoeck and Rosenberg, 1988). DeBoeck and Rosenberg note that hierarchical classification closely resembles, but has certain advantages over, a Boolean Cluster analysis. The specific self-structure measures produced by this statistical procedure are described below.

Table 1 A hypothetical selves $\times$ description matrix for a college student

\begin{tabular}{|c|c|c|c|c|c|c|c|}
\hline \multirow[b]{2}{*}{ Selves } & \multicolumn{6}{|c|}{ Description } & \multirow[b]{2}{*}{ Sociabl } \\
\hline & Caring & Close & $\begin{array}{l}\text { Easy to } \\
\text { be with }\end{array}$ & Diligent & $\begin{array}{l}\text { Family- } \\
\text { oriented }\end{array}$ & Kind & \\
\hline Brother/sister & & 1 & 1 & & 1 & & \\
\hline Friend & & 1 & 1 & & & 1 & 1 \\
\hline Healthy person & & 1 & 1 & & & & \\
\hline Helper & 1 & & & 1 & & 1 & \\
\hline My ideal self & & & & & 1 & 1 & 1 \\
\hline My self as I usually am & 1 & 1 & 1 & 1 & & 1 & 1 \\
\hline Neighbor & & & & & & 1 & 1 \\
\hline Romantic partner & & & & & & 1 & 1 \\
\hline Son/daughter & & & & & 1 & & \\
\hline Student & 1 & & & 1 & & 1 & 1 \\
\hline Worker & 1 & & & 1 & & 1 & \\
\hline
\end{tabular}




\section{Measures}

Hierarchical classification permits analysis of an individual's self-structure (Rosenberg and Gara, 1985). Morris Rosenberg (1979) observed that self-concept researchers have tended to neglect the idiographic aspects of self-concept and instead typically use nomothetic self-assessment measures that "ask respondents how intelligent, good-looking, likable, moral or neurotic they are without even bothering to determine how much the respondent cares about these characteristics" (p. 282). Critics have noted the inherent biases in using self-report assessment protocols to evaluate social relations (see, e.g. Allen et al., 1994). However, because the relationships between the different social selves are not self-reported but instead are calculated statistically by HICLAS, the settheoretical model provides a naturalistic and free-response method to study the multiplicity and structure of the self at an idiographic level (DeBoeck and Rosenberg, 1988). The graphical representation of self-structure created by HICLAS depicts three categories of information generated by the set-theoretic relationships of social selves: classes, connections, and levels. Moreover, a number of researchers have shown the HICLAS approach to be related significantly to theoretically relevant variables (e.g. Robey et al., 1989; Haviland et al., 1994) and there is evidence for the structure of social selves in late adolescence (e.g. Rosenberg and Gara, 1985; Berzonsky and Neimeyer, 1988; Byrne and Shavelson, 1996); thus, these prior studies show evidence of construct validity.

Classes. The first type of information gathered from the HICLAS depiction concerns the classes of selves or descriptions, which denote clusters of selves or descriptions. If two social selves were associated with approximately the same set of descriptions, then these two social selves comprise one self-class. A self-class may consist of one, two, or more social selves. For example, in Table 1, "worker" and "helper" are both associated with the same descriptions ("caring," "diligent," and "kind"). Consequently these two selves are clustered together into one self-class, as shown in Figure 1. However, because many sets of selves or descriptions do not entirely overlap, dissimilar self-classes or description-classes are likely to contrast with one another; thus, different clusters of selves or descriptions are generated (e.g. "friend" and "son/daughter"). Figure 1 portrays nine self-classes and five description classes in total.

Connections. A second set of interrelationships involves conceptual connections between the classes. Rosenberg and Gara (1985) note that one self-class might be "... dependent on some of the subidentities for its meaning to the person and for its enactment. .." (p. 94). In other words, a selfclass might be a subset of another self-class as based on the description ratings. In this case, the former would be dependent on the latter, and the HICLAS graphical self-structure would depict a connection between the two. To illustrate, in Figure 1, "student" is dependent on a number of subidentities in order to derive its meaning ("helper", "worker", "neighbor", and "romantic partner") and therefore has self-connections with each. It is also important to note that connections exist between the self-classes rather than between the individual social selves. In this Figure, there are 10 self-connections and two description-connections in total. Furthermore, isolated self-classes can be measured, which are those self-classes that have no connections at all to other classes. Rosenberg and Gara (1985) refer to isolated self-classes as "residuals" because they are conceptually independent. In Figure 1, there are no isolated self-classes because each self-class is connected with at least one other self-class. 


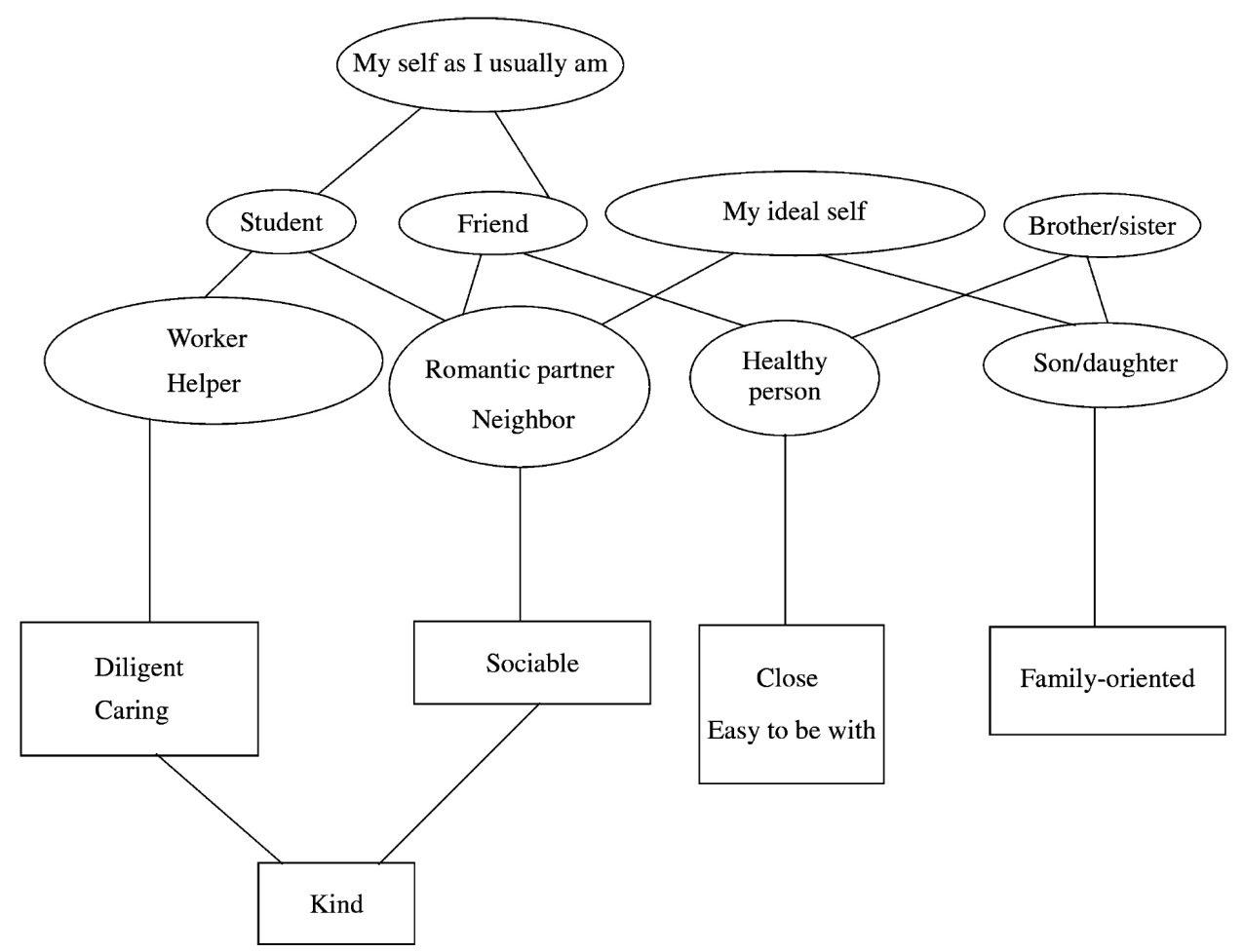

Figure 1. HICLAS representation for college student. Circles represent the self class, squares represent the description class and the connections are shown as a line.

Levels. The third set of relationships involves the levels of selves and of the descriptions in the hierarchy depicted in HICLAS. Like classes, levels consist of different selves or descriptions that cluster together, but unlike classes, levels cluster these more broadly, based on the connections between classes. In Figure 1, there are three self-levels and two description-levels. Investigators have also examined the selves above the bottom level of the hierarchical representation, which are called "superordinate" selves (Fransella and Bannister, 1977; see generally, Rosenberg and Gara, 1985). The notion of superordinate selves originated with Kelly (1955), who asserted that some identities are perceived as more salient and significant to an individual than are others. As applied to HICLAS set-theoretic modeling, a self is superordinate if it is in a self-class connected to any lower level self-class (Robey et al., 1989). In applying the concept of superordinate selves to HICLAS self-structure, Robey et al. maintained that selves which others depend upon would be perceived to be more important and salient. Thus, it is thought that information regarding the number of an individual's more prominent or primary selves can be gathered with HICLAS. Figure 1 shows five selves that are superordinate, the most salient of which is "my self as I usually am."

HICLAS self-structure. Information about social self and description-classes, connections, and levels constitutes an individual's self-structure in HICLAS. In this study, four self-structure measures were thought to reflect self-integration. Most obviously, the number of self-connections con- 
noted the degree to which different selves are conceptually related to one another. Additionally, self-integration was measured by the percentage of isolated self-classes, which was the number of isolated self-classes divided by the number of total self-classes. It was also maintained that the more superordinate selves, the less an individual consolidated the selves that were most important; thus, the fewer superordinate selves, the more integrated an individual was considered. The percentage of superordinate selves was calculated by dividing the number of superordinate selves by fourteen, the total number of selves in this study. Finally, because Harter et al. (1997) suggests that how one coordinates one's selves could relate to how one processes conceptual information, the number of description-connections was thought to provide a measure of self-integration.

Self-differentiation was depicted by two HICLAS self-structure variables. In particular, the number of self-classes and self-levels were thought to indicate how many different categories of selves an individual associated him/herself with. The remaining two measures, the number of description-classes and the number of description-levels, were necessary for the purposes of constructing the HICLAS self-structures. It is not clear how either is related to self-integration or to self-differentiation. Two research assistants thus examined each participant's HICLAS self-structure and coded the following eight measures: number of self-classes, self-connections, self-levels, description-classes, description-connections, description-levels, percentage of superordinate selves, and percentage of isolated self-classes.

\section{Results}

Group means and standard deviations for the eight self-structure variables are shown in Table 2. Analyses of variance were conducted on the self-structure variables for each participant group. Data indicated that variation among the means of measures was different significantly between first year and fourth year college students on two HICLAS measures of self-integration. Participants in the first year of college showed significantly fewer self-connections than participants in the fourth year of college $(F(1,127)=18.10, p=0.001)$, indicating that fourth-year students in the sample perceived the characteristics of different selves to overlap more than did first-year students.

Conversely, participants in the first year group demonstrated a significantly higher percentage of isolated self-classes than those in the fourth year group $(F(1,127)=4.30, p=0.040)$. This finding implies that the first-year college students in the sample perceived more of their social selves to be independent of their other social selves as compared with the fourth year students.

It should be noted, however, that the percentage of superordinate selves was not different significantly between the first- and fourth-year groups. Both groups perceived approximately the same mean number of social selves as salient, given the list of fourteen social selves provided in the stimulus. Additionally, although the number of description connections was greater for fourth-year participants compared with first-year participants, this difference approached but did not achieve statistical significance $(F(1,127)=2.87, p=0.092)$. The conceptual relationships between description classes were about the same throughout the sample of college students.

Analyses showed that fourth-year students showed greater differentiation of selves than firstyear students. Both the number of self-classes $(F(1,127)=16.67, p=0.001)$ and the number of selflevels $(F(1,127)=14.64, p=0.001)$ were significantly higher for the fourth-year group as compared 
Table 2 HICLAS self-structure measures for first- and fourth-year college students

\begin{tabular}{|c|c|c|c|c|c|c|c|}
\hline \multirow[b]{2}{*}{ Self-structure measures } & \multicolumn{2}{|c|}{$\begin{array}{c}\text { First year } \\
\text { college students }\end{array}$} & \multicolumn{2}{|c|}{$\begin{array}{l}\text { Fourth year } \\
\text { college students }\end{array}$} & \multirow[b]{2}{*}{$F$} & \multirow[b]{2}{*}{$p$} & \multirow[b]{2}{*}{$E t a^{2}$} \\
\hline & $\mathrm{M}$ & S.D. & $\mathrm{M}$ & S.D. & & & \\
\hline Self-classes & 5.89 & 1.77 & 7.31 & 2.14 & 16.67 & 0.001 & 0.117 \\
\hline Self-connections & 4.62 & 2.92 & 6.98 & 3.30 & 18.10 & 0.001 & 0.126 \\
\hline Self-levels & 2.99 & 0.73 & 3.53 & 0.86 & 14.64 & 0.001 & 0.104 \\
\hline Description classes & 6.52 & 1.42 & 7.28 & 1.90 & 8.56 & 0.004 & 0.064 \\
\hline Description connections & 5.22 & 1.96 & 5.88 & 2.44 & 2.87 & 0.092 & 0.022 \\
\hline Description levels & 3.29 & 0.69 & 3.41 & 0.88 & 0.83 & 0.364 & 0.007 \\
\hline \% Isolated self-classes & 9.76 & 18.13 & 4.20 & 7.54 & 4.30 & 0.040 & 0.030 \\
\hline \% Superordinate selves & 65.12 & 24.82 & 69.61 & 22.26 & 1.09 & 0.299 & 0.009 \\
\hline
\end{tabular}

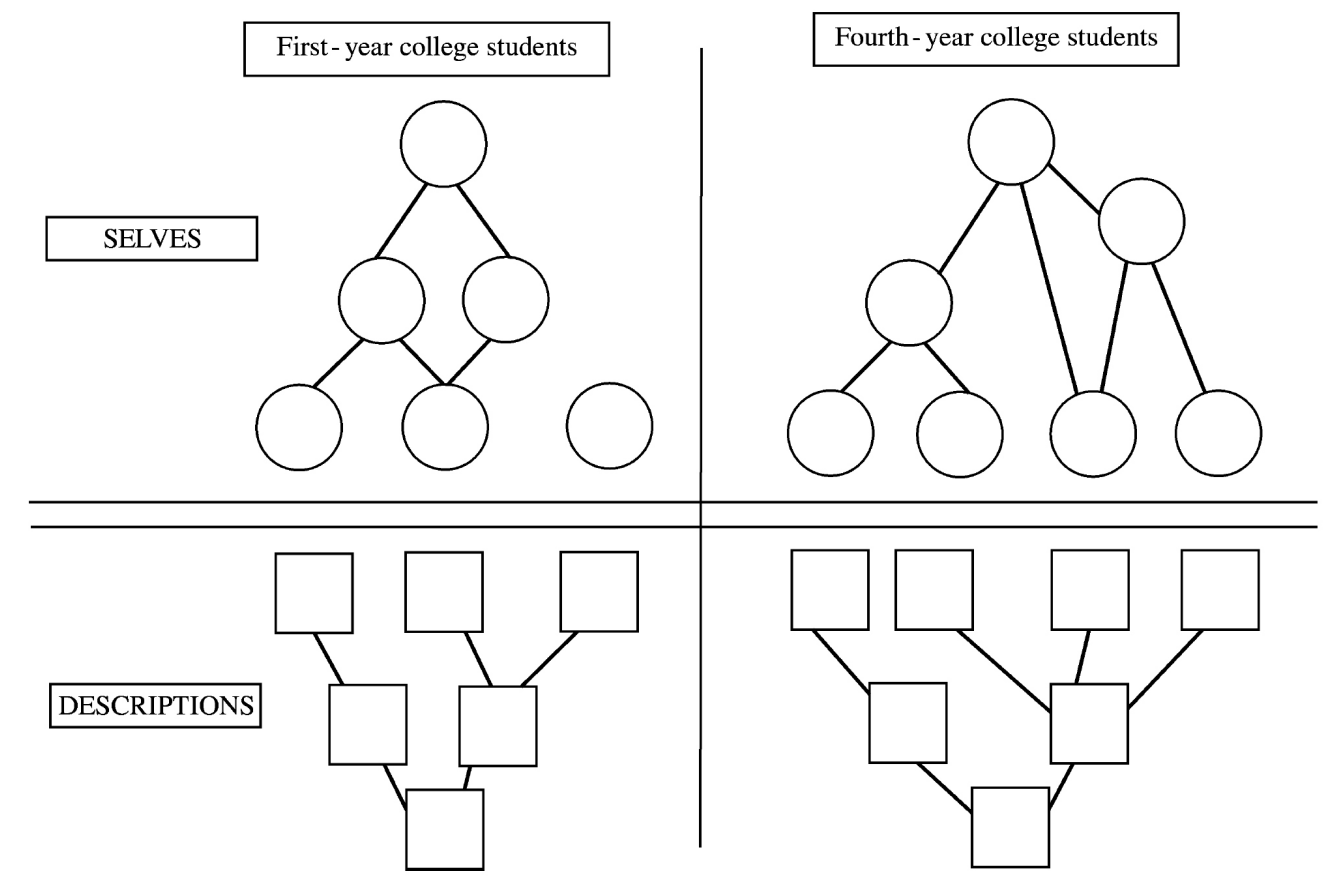

Figure 2. Graphic depiction of prototypical first-year and fourth-year college student based on HICLAS self-structure variable means. Circles represent the self class, squares represent the description class and the connections are shown as a line.

with the first-year group. This suggests that the fourth-year college students in the sample identified with more social selves than did the first-year students and were better able to make distinctions among the 14- social selves provided in the stimulus.

Follow-up analyses were also conducted comparing gender differences on HICLAS self-structure variables. Results showed that female participants $(M=61.98$, S.D. $=25.30)$ had a significantly lower mean on percentage of superordinate selves than male participants $(M=70.66$, S.D. $=21.37)$, $\mathrm{F}(1,176)=4.51, \mathrm{p}=0.035$. However, no significant differences were found with respect to gender 
on the other seven self-structure variables examined in this study. Gender-College Year interactions were examined for the eight self-structure variables, but were not found to be significant.

Two other self-structure variables were coded for the purposes of constructing the HICLAS self-structures. Description-classes were shown to differ significantly between first- and fourthyear students $(F(1,127)=8.56, p=0.004)$ though description-levels did not differ. Based on these, and the six other self-structure variables, a visual representation of the comparison between firstand fourth-year college students was constructed and is depicted in Figure 2. The figure represents a prototypical first- or fourth-year student in our sample, based on means obtained from each group in the sample. The means on the self-structure variables found in Table 2 were rounded to the nearest integer to permit graphic representation.

Although self-levels, self-connections, self-classes, description-levels, description-connections, and description-classes are readily portrayed in Figure 2, it was comparatively more difficult to capture the percentage of isolated selves and the percentage of superordinate selves in graphic form. As a result, isolated self-classes (self-classes with no connections to other self-classes) were substituted for percentage of isolated self-classes in order to illustrate the difference in percentage of isolated selves found between first and fourth year participants. As can be seen in Figure 2, representation of social selves was more complex and interconnected for fourth-year students as compared with first-year students.

\section{Discussion}

Consistent with theories of identity formation proposed by Marcia (1966) and Waterman (1988), the present results suggest that multi-dimensional, hierarchical self-structures as measured by HICLAS are more integrated in fourth-year college students as compared to first-year students. The differences found between first- and fourth-year students indicate that representations of social selves can be used to distinguish self-concept between these two groups. With HICLAS self-structure representations, students of more advanced years showed significantly greater number of self-connections than first-year students. Fourth-year college students defined more social selves as subsets of other selves as compared with first-year college students.

Additionally, the findings demonstrated that younger students displayed a significantly greater percentage of isolated selves relative to older students. Overall, older students appeared to draw more upon attributes, characteristics, and descriptions from other social roles than younger students. As postulated by Epstein (1973), self-concept appears to become more consolidated across development.

The number of description connections was higher for the fourth-year group, seeming to provide some empirical support for the claim made by Harter et al. (1997) that the coordination of self would be more likely in later adolescence due to increased abilities in abstract thinking. However, the difference between first- and fourth-year students on description connections was not significant. Further, the percentage of superordinate selves was approximately equivalent for first and fourth year college students. It was assumed that the lower the percentage of superordinate selves and the greater the number of description connections, the greater the integration of self. Some scholars have suggested that both self-structure variables relate to a form of conceptual sophistication called cognitive complexity (Fransella and Bannister, 1977). While it is not clear whether 
"cognitive-complexity" is comparable to the notion of "self-integration", given the other findings in this study, more investigation into these two HICLAS measures seems warranted.

Fourth-year college students in the sample did exhibit a greater differentiation of the multiple selves as compared with first-year college students on HICLAS self-structure variables. Results were consistent with Berzonsky's (1989) study that found an increased differentiation of social selves in students over the college years. However, Marsh (1990), who examined subjects in the same age range as this current study, could not conclude that there was differentiation of multidimensional hierarchical self beyond adolescence. One reason for this discrepancy in the findings could be the use of different types of methodology. Additionally, some scholars have noted that, in general, late adolescence and young adulthood has been studied less as compared with early and mid-adolescence (see e.g. Sherrod et al., 1993; O'Connor et al., 1996). So, although self-differentiation during early and mid-adolescence is well-established (Damon and Hart, 1982), relatively less work has addressed the hypothesis that this process continues into adulthood.

There were no gender differences found on the HICLAS self-structure variables except on percentage of superordinate selves. Examining superordinate selves has been central to HICLAS because it is postulated that some selves will be more significant and important to an individual than other selves (Kelly, 1955; Robey et al., 1989). Findings in this study indicated that men identified a significantly greater number of social selves than did women. One possible explanation for this difference could be the choice of the social selves utilized. Perhaps men identified more with the 14 selves provided in this study than did women. In this case, another study using the same methodology with different social selves would seem warranted.

Another alternative is suggested by other researchers. Harter et al. (1997) stated that although no gender differences were initially anticipated in their studies, they indicated that adolescent females did report significantly more opposites and conflicts on social selves than did adolescent males (see, e.g. Harter and Monsour, 1992). This greater conflict could be reflected in the present study by the finding that women perceived approximately half of the social selves as important (superordinate) and the other half as less important. Men, on the other hand, appeared to have more of their social selves positioned on the same superordinate, hierarchical plane. This implies that men and women might not differ so much in the extent to which their multiple selves were integrated, but in the way in which they accentuated the integration of their social selves. This points to the possibility that gender might influence the process of self-integration during one's college years.

There were several limitations of this study that should be noted. First, there was little variation in the ethnicity and cultural backgrounds of the students; thus, any generalizations of the present findings to all college students must be made tentatively. Second, future research efforts need to examine whether HICLAS measures compare and correlate with other instruments used by social and developmental researchers (see Grotevant and Adams, 1984). For example, in order to establish more valid operational measures of self-integration, it is important to compare HICLAS self-structures with related constructs such as Linville's (1985) theory of self-complexity. Third, the present study involved college students and did not consider individuals of the same age range who were not attending college. That is, while the study examined the transition from late adolescence to young adulthood, it is restricted to this transition in college students. Furthermore, it is important to recognize that students taking an introductory psychology class in their fourth year 
are non-psychology majors, whereas first-year students would probably represent a more heterogeneous group, including future psychology majors. Thus, there may be different reasons why these two groups of students took the class. And fourth, because the comparisons were based on a cross-sectional design, it cannot be determined whether a particular individual's different selves become more integrated or differentiated over time. As such, this study focused less on developmental change but rather on age/cohort differences. Longitudinal studies with more diverse samples are needed to study whether self-structure indeed becomes more differentiated or integrated across the transition from late adolescence to young adulthood.

Future directions for research might be to examine the specific selves that were clustered. Which social selves were perceived as most salient in the college sample? Which ones were not seen as salient? Might first-year and fourth-year students have rated different social selves as superordinate? If so, which ones? It is also possible that some selves were more likely to be isolated from or connected to other selves in college students. Were there specific selves that tended to be isolated in first year or fourth year college students or between males and females? Finally, different superordinate selves or isolated selves may be associated with greater or lesser integration or differentiation of self. Much work can be done to examine the changes in self-structure over the college years.

In summary, prior to the present study, HICLAS self-structure procedures had been used predominantly to compare the self-concept of clinical populations to normal controls. Some preliminary studies indicated that HICLAS could be used viably to examine the self-organization of college students. This study attempted to expand upon this work by using HICLAS procedures to compare multidimensional self-structures among late adolescents and young adults. As expected, the results indicated that multiple social selves were more consolidated and differentiated in college students of more advanced years. These findings were consistent with prior theories of adolescent self-concept development. Thus, the results suggested that the use of HICLAS procedures can be an informative and useful tool for exploring developmental hypotheses in the future.

\section{Acknowledgment}

Funding for Gustavo Carlo was provided by a grant from the Gallup Research Center. The authors wish to thank Tara Elbogen and Monica Wilson for their assistance and comments on an earlier version of this manuscript.

\section{References}

Adams-Weber, J. (1985). Self-other contrast and the development of personal constructs. Canadian Journal of Behavioral Science, 14, 303-314.

Allen, J. P., Hauser, S. T., Bell, K. L., and O'Connor, T. G. (1994). Longitudinal assessment of autonomy and relatedness in adolescent-family interactions as predictors of adolescent ego development and self-esteem. Child Development, 65, 179-194.

Berger, K. S. (1994). The Developing Person through the Life Span. New York: Worth Publishers.

Berzonsky, M. D. (1989). The self as theorist: individual differences in identity formation. International Journal of Personal Construct Psychology, 2, 363-376. 
Berzonsky, M. D., and Neimeyer, G. J. (1988). Identity status and personal construct systems. Journal of Adolescence, 11, 195-204.

Byrne, B. M., and Shavelson, R. J. (1996). On the structure of social self-concept for pre-, early-, and late adolescents: a test of the Shavelson, Hubner, and Stanton (1976). Journal of Personality and Social Psychology, 70, 599-613.

Conway, M., and White-Dysart, L. (1999). Individual differences in attentional resources and self-complexity. Social Cognition, 17, 312-331.

D’ Andrade, R. G. (1976). A propositional analysis of U.S. American beliefs about illness. In Meaning in Anthropol$o g y$, K. H. Basso and H. A. Selby (Eds). Albuquerque: University of New Mexico Press, pp. 155-180.

Damon, W., and Hart, D. (1982). The development of self-understanding from infancy through adolescence. Child Development, 53, 841-864.

DeBoeck, P. (1986). HICLAS: Version 1.0 [Computer Program]. Leuven, Belgium: Katholieke Universitat Leuven, Psychology Department.

DeBoeck, P., and Rosenberg, S. (1988). Hierarchical classes: model and data analysis. Psychometrika, 53, 361-381.

Epstein, S. (1973). The self concept revisited or the theory of a theory. American Psychologist, 28, 405-416.

Erikson, E. (1968). Identity, Youth, and Crisis. New York: Norton.

Fischer, K. W. (1980). A theory of cognitive development: the control and construction of hierarchies of skills. Psychological Review, 87, 477-531.

Fransella, F., and Bannister, D. (1977). A Manual for Repertory Grid Technique. London: Academic Press.

Gara, M. A., Rosenberg, M. A., and Mueller, D. R. (1989). Perception of self and other in schizophrenia. International Journal of Personal Construct Psychology, 2, 253-270.

Gara, M. A., Rosenberg, S., and Cohen, B. D. (1987). Personal identity and the schizophrenic process: an integration. Psychiatry, 50, 267-278.

Gara, M. A., Woolfolk, R. L., Cohen, B. D., and Goldston, R. B. (1993). Perception of self and other in major depression. Journal of Abnormal Psychology, 102, 93-100.

Grotevant, H. D. (1987). Toward a process model of identity formation. Journal of Adolescent Research, 2, 203-222.

Grotevant, H. D., and Adams, G. R. (1984). Development of an objective measure to assess ego development in adolescence: validation and replication. Journal of Youth and Adolescence, 13, 419-438.

Harter. S. (1983). Developmental perspectives on the self-system. In Handbook of Child Psychology, 4: Socialization, Personality, and Social Development, M. Hetherington (Ed.). New York: Wiley, pp. 275-386.

Harter. S., Bresnick, S., Bouchey, H. A., and Whitesell, N. R (1997) The development of multiple role-related selves during adolescence. Development and Psychopathology, 9, 835-853.

Harter, S., and Monsour, A. (1992). Developmental analysis of conflict caused by opposing attitudes in the adolescent self-portrait. Developmental Psychology, 28, 251-260.

Haviland, J. M., Davidson, R. B., Ruetsch, C., and Gebelt, J. L. (1994). The place of emotion in identity. Journal of Research on Adolescence, 4, 503-518.

James, W. (1890). The Principles of Psychology. New York: Holt.

James, W. (1892). Psychology: the briefer course. New York: Holt, Rinehart \& Winston.

Kelly, G. A. (1955). The psychology of personal constructs. New York: Norton.

Linville, P. W. (1985). Self-complexity and affective extremity: don't put all of your eggs in one cognitive basket. Social Cognition, 3, 94-120.

Linville, P. W. (1987). Self-complexity as a cognitive buffer against stress-related illness and depression. Journal of Personality and Social Psychology, 52, 663-676.

Marcia, J. E. (1966). Development and validation of ego identity status. Journal of Personality and Social Psychology, 3, 551-558.

Markus, H. and Smith, J. (1982). The influence of self-schema on the perception of others. In Personality, cognition and social interaction, N. Cantor and J. F. Kihlstrom (Eds). Hillsdale, NJ: Erlbaum. 
Markus, H., and Nurius, P. (1986). Possible selves. American Psychologist, 41, 954-969.

Markus, H., and Wurf, E. (1987). The dynamic self-concept: a social psychological perspective. Annual Review of Psychology, 38, 299-337.

Marsh, H. W. (1986). Global self-esteem: its relation to specific facets of self-concept and their importance. Journal of Personality and Social Psychology, 51, 1224-1236.

Marsh, H. W. (1990). A multidimensional, hierarchical self-concept: theoretical and empirical justification. Educational Psychology Review, 2, 77-172.

Mechelen, I. V., and DeBoeck, P. (1995). The conjunctive model of hierarchical classes. Psychometrika, 60, 505-521.

Montemayor, R., and Eisen, M. (1977). The development of self-conceptions from childhood to adolescence. Developmental Psychology, 13, 314-319.

O'Connor, T. G., Allen, J. P., Bell, K. L., and Hauser, S. T (1996). Adolescent-parent relationships and leaving home in young adulthood. New Directions for Child Development, 71, 39-52.

Ogilvie, D. M., Fleming, C. J., and Pennel, G. E. (1998). Self-with-other representations. In Advanced Personality: the Plenum Series in Social/Clinical Psychology, D. F. Barone and M. Hersen (Eds). New York: Plenum Press, pp. 353-375.

Robey, K. L., Cohen, B. D., and Gara, M. A. (1989). Self-structure in schizophrenia. Journal of Abnormal Psychology, 98, 436-442.

Rosenberg, M. (1979). Conceiving the Self. New York: Basic Books.

Rosenberg, S., and Gara, M. A. (1985). The multiplicity of personal identity. In Review of Personality and Social Psychology, P. Shaver (Ed.). (Vol. 6, pp. 87-113). Beverly Hills, CA: Sage.

Sewell, K. W., and Heacock, D. (1991). OMNIGRID-PC. Version 1.5 [Computer Program]. Lawrence, Kansas: University of Kansas, Psychology Department.

Shavelson, R. J., Hubner, J. J., and Stanton, G. C. (1976). Self-concept: validation of construct interpretations. Review of Educational Research, 46, 407-441.

Sherrod, L. R., Haggerty, R. J. and Featherman, D. L. (1993). Introduction: late adolescence and the transition to adulthood. Journal of Research on Adolescence, 3, 217-226.

Strachan, A. and Jones, D. Changes in identification during adolescence: a personal construct theory approach. Journal of Personality Assessment, 46, 529-535.

Strage, A. A. (1998). Social and academic integration and college success: similarities and differences as a function of ethnicity and family educational background. College Student Journal, 33, 198-205.

Waterman, A. S. (1988). Identity status theory and Erikson's theory: communalities and differences. Developmental Review, 8, 185-208. 